\title{
Acquisition, Retention, and Recall of Memory After Injection of RS67333, a 5-HT4 Receptor Agonist, Into the Nucleus Basalis Magnocellularis of the Rat
}

\author{
Marco Orsetti, ${ }^{1,3}$ Anna Dellarole, ${ }^{1}$ Simona Ferri, ${ }^{2}$ and Piera Ghi ${ }^{2}$ \\ ${ }^{1}$ Dipartimento di Scienze C.A.F. e Farmacologiche, Università del Piemonte Orientale, 28100 Novara, Italy; ${ }^{2}$ Dipartimento di \\ Anatomia, Farmacologia e Medicina Legale, Università di Torino, 10125 Torino, Italy
}

\begin{abstract}
The serotonin 5-HT4 subtype receptor is predominantly localized into anatomical structures linked to memory and cognition. A few experimental studies report that the acute systemic administration of selective 5-HT4 agonists has ameliorative effects on memory performance, and that these effects are reversed by contemporary administration of 5-HT4 receptor antagonists. To verify whether this procognitive action occurs via the activation of the cholinergic nucleus basalis magnocellularis (NBM)-cortical pathways, we examined the effects of RS67333, a selective partial agonist of the 5-HT4 receptor, on rat performance in a place recognition task upon local administration of the drug into the NBM area. The intra-NBM administration of RS67333 enhances the acquisition (200-500 ng/0.5 $\mu \mathrm{L}$ ) and the consolidation $(40-200 \mathrm{ng} / 0.5 \mu \mathrm{L}$ ) of the place recognition memory. These effects are reversed by pretreatment

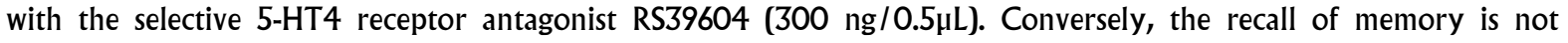
affected by the 5-HT4 agonist. Our results indicate that 5-HT4 receptors located within the NBM may play a role in spatial memory and that the procognitive effect of RS67333 is due, at least in part, to the potentiation of the activity of cholinergic NBM-cortical pathways.
\end{abstract}

The putative role of the serotonergic system in memory improvement or recovery from impaired cognitive performance has received considerable attention over the last years. In this context, radioligand binding and autoradiography studies performed in different animal species revealed that the serotonin 5-HT4 subtype receptor, a G-protein-coupled receptor activating the adenylate cyclase system, is predominantly localized in anatomical structures linked to memory and cognition (Eglen et al. 1995b; Waeber et al. 1996). In addition, direct evidence of the physiological relevance of 5-HT4 subtype receptors in learning and memory processes has been reported by several authors (Fontana et al. 1997; Letty et al. 1997; Marchetti-Gauthier et al. 1997; Meneses and Hong 1997; Galeotti et al. 1998; Marchetti et al. 2000; Lamirault and Simon 2001; Lelong et al. 2001). Moreover, a decline of 5-HT4 sites labeled with $\left[{ }^{3} \mathrm{H}\right]-\mathrm{GR} 113808$ in the hippocampus and cerebral cortex of patients with Alzheimer's disease was observed by Reynolds et al. (1995).

Generally, the systemic administration of 5-HT4 agonists has ameliorative effects on memory performance, and these effects are reversed by contemporary administration of 5-HT4 receptor antagonists. A possible interpretation of the memory-enhancing properties of 5-HT4 agonists is in terms of a facilitation of the central cholinergic activity, as these drugs revert the cognitive deficit induced by atropine in the Morris water maze (Fontana et al. 1997) and the scopolamine-induced amnesia in the mouse passive avoidance test (Galeotti et al. 1998).

More direct evidence of a putative modulatory role of 5-HT4 receptors on cholinergic function is that in vivo, BIMU-1 and BIMU-8, two mixed 5-HT3 antagonists/5-HT4 agonists, increase extracellular levels of acetylcholine in the rat frontal cortex (Con-

\section{${ }^{3}$ Corresponding author.}

E-MAIL orsetti@pharm.unipmn.it; FAX +390321 689821.

Article and publication are at http://www.learnmem.org/cgi/doi/10.1101/ Im.67303. solo et al. 1994). Siniscalchi et al. (1999) confirmed these findings in electrically stimulated slices of cerebral cortex, hippocampus, and nucleus basalis magnocellularis (NBM) of the rat by measuring the modifications of the electrically triggered $\left[{ }^{3} \mathrm{H}\right]$-choline efflux induced by BIMU-8.

In rodents, the term NBM is used to designate cholinergic cells that are diffusely distributed along the ventral and lateral borders of the internal capsula, in the ansa lenticularis, and along the medial border of the pallidum. This nucleus is thought to be homologous to the nucleus basalis of Meynert in primates, and provides a major, topographically organized input to the cortical mantle.

Neuroanatomical evidence of a putative serotonergic modulation of the NBM cholinergic activity was reported by Gasbarri et al. (1999). They identified, at the light microscopy level, tryptophan hydroxylase-immunoreactive terminals in close contact with cholinergic elements of the NBM and, using the Fluoro Gold retrograde tracer technique, they demonstrated that the NBM serotonergic afferents derive primarily from the B7 cell group of the dorsal raphe nucleus. Experimental lesions of the NBM in the rat are frequently associated with impairment of learning and memory in a wide variety of tasks (Dekker et al. 1991; Baxter et al. 1995; Leanza et al. 1996), suggesting that NBM neurons are involved in these processes.

On the basis of these results, it might be argued that the procognitive effects of 5-HT4-selective agonists derive, at least in part, by the activation of the cholinergic NBM-cortical pathways.

To gain a better understanding of the relationships between the role of serotonin 5-HT in particular brain structures and defined cognitive functions, we investigated the modifications of spatial short-term memory caused by preacquisition, postacquisition, and preretrieval infusion into the NBM area of two selective drugs, RS67333 (1-[4-Amino-5-chloro-2-methoxyphenyl]-3-[1butyl-4-piperidinyl]-1-propanone) and RS39604 (1-[4-Amino5-chloro-2-\{3,5-dimethoxyphenyl\}methyloxy]-3-[1-\{2-methylsul- 
phonylamino]ethyl\}piperidin-4-yl]propan-1-one) that activate or inactivate 5-HT4 receptors.

The two compounds show high affinity $\left(\mathrm{RS} 67333 \mathrm{pK}_{\mathrm{i}}=8.7\right.$ and RS39604 $\mathrm{pK}_{\mathrm{i}}=9.1$ ) for the 5-HT4 binding sites labeled with [3H]-GR 113808 in guinea pig striatal membranes (Eglen et al. 1995a; Hedge et al. 1995) and behave as a 5-HT4-selective antagonist (RS39604) or partial agonist (RS67333, intrinsic activity 0.5 with respect to $5-\mathrm{HT}$ ) in functional studies.
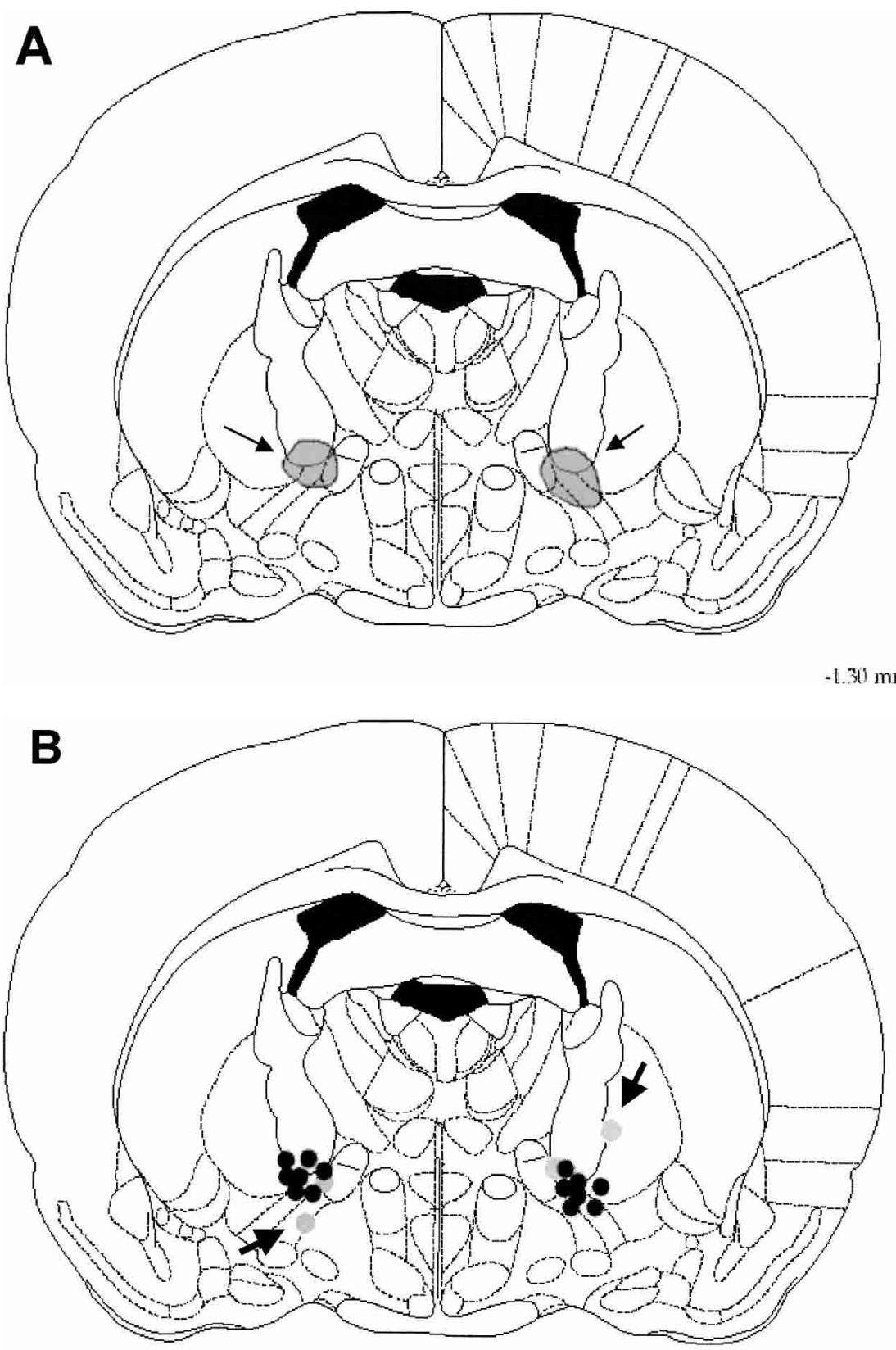

Figure 1 To estimate the range of diffusion of RS67333 and RS39604 following local intra-NBM injection, blue dye was infused at the same rate as drugs. The gray areas in the coronal section $(A)$ match the approximate distribution of the dye $10 \mathrm{~min}$ after bilateral infusion in a single rat. (B) The location of intracranial injection sites of a representative experiment $(n=9)$. Black circles represent "good" and gray circles represent "lost" animals (see the text for details). Data from rats that did not have both cannulae in the target zone (arrows) were not included in the behavioral analysis. Drawings reproduced from the atlas of Paxinos and Watson (1998).
$-1.30 \mathrm{~mm}$

$-1.30 \mathrm{~mm}$

\section{RESULTS}

Histological verification of injection sites of the animals that had completed the place recognition task was carried out by an obver blind to the behavioral results. A rat was classified as "good" when tips of both injection cannula tracks were within the area of the NBM and was classified as "lost" when one or both injection cannula tips were outside of the target area (Fig. 1B). All behavioral analyses reported in the present study were based on animals classified as "good."

\section{Effects of Intra-NBM Injection of Saline, RS67333, and RS39604}

The global analysis of data concerning saline-treated rats, operated and tested one week later $(\mathrm{n}=29)$ indicated significant retention time (F $2 / 26=5.77 ; P=0.008)$, arm (F $2 / 52=34.4 ; P<0.001$ ), and retention time $\times$ arm (F $4 / 52=8.3 ; P<0.001$ ) effects (Fig. 2 ). The number of visits to the novel arm was higher for the 60-min (F 2/16 = 14.5; $P<0.001 ; \mathrm{n}=9$ ) and $120-\min (\mathrm{F} 2 / 18=68.9$; $P<0.001 ; \mathrm{n}=10)$ groups but not for the 180 min interval group (F $2 / 18=0.04 ; P=0.96$; $\mathrm{n}=10$ ).

On the basis of these results, the drugs were tested for their promnestic or amnestic effects respectively at 180 - or 120 -min intertrial intervals. The 5-HT4 antagonist RS39604 (300 ng), infused preacquisition, postacquisition, and preretrieval into the NBM, produced no modifications of the rats' performance at both 120-min (F 3/25 $=0.31$; $P=0.82 ; \mathrm{n}=29)$ and $180-\min (\mathrm{F} 3 / 27=0.11$; $P=0.96 ; \mathrm{n}=31$ ) intertrial intervals. Conversely, the intra-NBM injection of RS67333 had ameliorative effects on the place recognition memory (Figs. 3,4).

A significant effect of the treatment on rat performance was obtained after preacquisition (F $3 / 32=7.03 ; P=0.001 ; \mathrm{n}=36$ ) or postacquisition (F $3 / 34=11.02 ; P<0.001$; $\mathrm{n}=38$ ) administration of the 5-HT4 partial agonist. The preretrieval infusion of the drug was ineffective (F 2/23 $=0.68 ; P=0.51$; $\mathrm{n}=26$ ). A one-way ANOVA and Scheffè test indicated that the number of visits to the novel arm was higher in groups treated preacquisition with RS67333 $200 \mathrm{ng}$ (F $2 / 14=15.5 ; P<0.001 ; \mathrm{n}=8)$ and $500 \mathrm{ng}(\mathrm{F}$ $2 / 16=11.3 ; P<0.001 ; \mathrm{n}=9$ ) or postacquisition with 40 and $200 \mathrm{ng}$ (respectively: $\mathrm{F}$ $2 / 18=7.5 ; \quad P=0.004 ; \quad \mathrm{n}=10 \quad$ and $\mathrm{F}$ $2 / 16=10.6 ; P=0.001 ; \mathrm{n}=9)$.

\section{Time Course of RS67333}

\section{Postacquisition Effect}

It can be seen in Figure 5 that the improvement of memory caused by the local infusion of $200 \mathrm{ng}$ of RS67333 postacquisition was time-dependent. The overall ANOVA $(\mathrm{n}=27)$ revealed significant delay $(\mathrm{F}$ $2 / 24=8.95 ; P=0.0013)$, arm $($ F $2 / 48=20.32$; 
intra-NBM saline injection

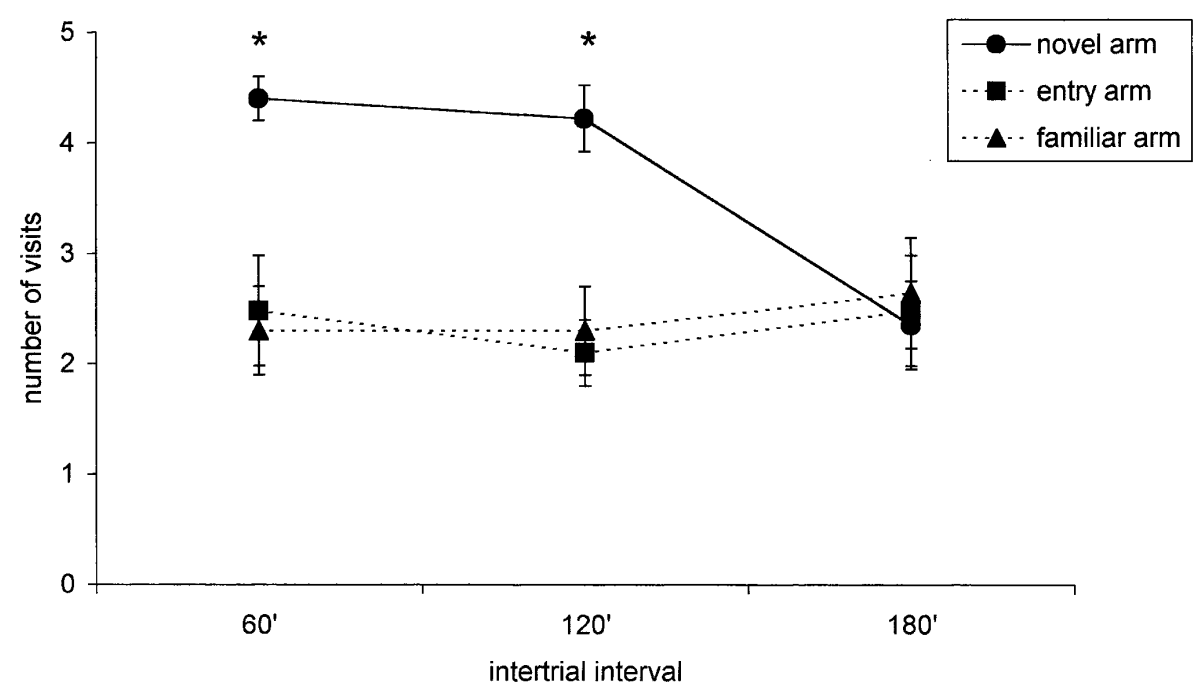

Figure 2 Place recognition memory $(n=29)$ : The saline was injected into the NBM to three different groups of rats and the animals were tested in a Y-maze at increasing time intervals (60 min, $n=9 ; 120$ min, $n=10 ; 180$ min, $n=10$ ) from the first trial (acquisition trial). The points indicate the number of visits for each arm (mean \pm standard error of the mean [s.e.m.]). The statistical analysis of data (see the text for details) indicates that, in the present experimental conditions, the memory lasts about $120 \mathrm{~min}$. ${ }^{*} P<0.05$ compared with the other two arms (Scheffè post hoc test).

$P<0.001)$, and delay $\times$ arm $(\mathrm{F} 4 / 48=8.51 ; P<0.001)$ effects. A 20-min delay did not affect the promnestic action of the drug ( $\mathrm{F}$ $2 / 14=19.1 ; P<0.001 ; \mathrm{n}=8$ ), whereas the effect of the $5-\mathrm{HT} 4$ agonist disappeared in the group injected $35 \mathrm{~min}$ after the end of first trial $(\mathrm{F} 2 / 18=2.05 ; P=0.157 ; \mathrm{n}=10)$.

\section{Effect of Intra-NBM Injection of RS67333 in Rats Pretreated With RS39604}

The procognitive effect of RS67333 (200 and $500 \mathrm{ng}$ ) infused preacquisition was abolished by prior treatment with 300 ng of RS39604 (Fig. 6). The statistical analysis indicated significant differences between the RS67333-200 ng group and the RS67333-200 ng + RS39604-300 ng group (F $1 / 37=28.9 ; P<0.001)$ and between the RS67333-500 ng group and the RS67333-500 ng + RS39604-300 ng group $(\mathrm{F} 1 / 37=4.85 ; P<0.001)$. Similar results were obtained after postacquisition intra-NBM treatment (Fig. 7). In these experiments, the statistical analysis indicated significant differences between the RS67333-40 ng group and the RS67333-40 ng + RS39604-300 ng group (F $1 / 35=20.5 ; P<0.001$ ), and between the RS67333-200 ng group and the RS67333-200 ng + RS39604-300 ng group $(\mathrm{F} 1 / 35=12.4 ; P=0.0012)$.

\section{DISCUSSION}

Several lines of evidence have suggested that there is a functional interaction between the cholinergic and serotonergic systems in the mediation of cognitive behavior (Sirvio et al. 1994; Cassel and Jeltsch 1995; Steckler and Sahgal 1995).

However, the initial studies reported some conflicting results about the role of the central 5-HT in learning and memory: These may be attributable to the application of a global strategy which modifies the whole serotonergic system and its interaction with other neurotransmitters, to the use of nonselective compounds, and to the systemic route of drug administration.

To better understand the relationships between the role of 5-HT in particular brain structures and defined cognitive functions, we investigated the modifications of spatial short-term memory caused by the local infusion (into the NBM) of two selective drugs, RS67333 and RS39604, that activate or inactivate a specific subtype (5-HT4) of 5-HT receptors.

Our results indicate that the local intra-NBM injection of RS67333 enhances the acquisition and the consolidation of place recognition memory. These effects were reversed by pretreatment with RS39604. Although the pharmacodynamic profile of RS67333 indicates that the compound has similar affinity for 5-HT4, $\sigma 1$, and $\sigma 2$ receptors $\left(\mathrm{pK}_{\mathrm{i}}=8.7,8.9\right.$, and 8.0, respectively; Eglen et al. 1995a), the antagonist RS39604 displays low affinity $\left(\mathrm{pK}_{\mathrm{i}}<6.5\right)$ for 5 -HT1A, 5-HT2C, 5-HT3, D1, D2, M1, M2, and $\mu$ receptors, low to moderate affinity for $\sigma 1\left(\mathrm{pK}_{\mathrm{i}}=6.8\right)$ and $\sigma 2\left(\mathrm{pK}_{\mathrm{i}}=7.8\right)$ receptors, and very high affinity for 5-HT4 sites $\left(\mathrm{pK}_{\mathrm{i}}=9.1\right.$; Hedge et al. 1995). Given the selectivity of RS39604 for 5-HT4 receptors and the fact

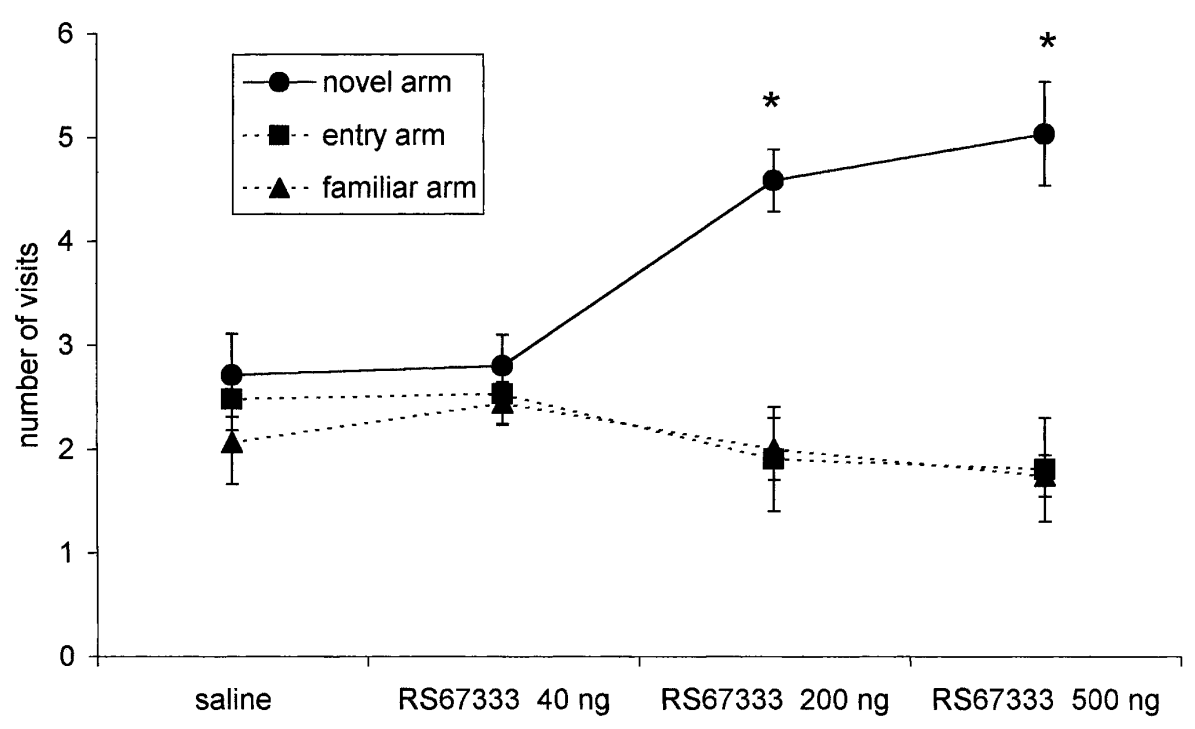

Figure 3 Effect of RS67333 on the place recognition memory $(n=36)$ : The intra-NBM injection of two increasing doses $(200 \mathrm{ng} / 0.5 \mu \mathrm{L}, \mathrm{n}=8 ; 500 \mathrm{ng} / 0.5 \mu \mathrm{L}, \mathrm{n}=9)$ of the drug 2 min prior to the beginning of the first trial (preacquisition treatment) improves memory. A lower dose $(40 \mathrm{ng} / 0.5 \mu \mathrm{L}$, $\mathrm{n}=10$ ) has no effect. The points indicate the number of visits for each arm (mean \pm s.e.m.). Intertrial interval, 180 min. ${ }^{*} P<0.05$ compared with the other two arms (Scheffè post hoc test).

\section{Learning \& Memory}


post-acquisition intra-NBM injection of RS67333

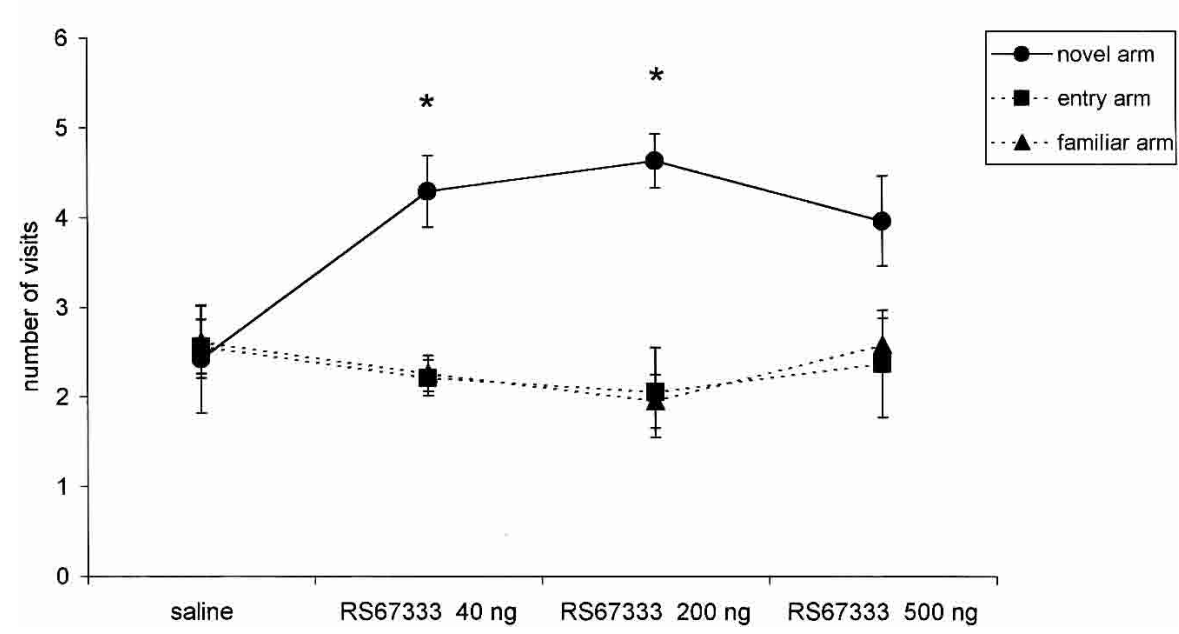

Figure 4 Effect of RS67333 on the place recognition memory $(n=38)$ : The intra-NBM injection of two increasing doses ( $40 \mathrm{ng} / 0.5 \mu \mathrm{L}, \mathrm{n}=10 ; 200 \mathrm{ng} / 0.5 \mu \mathrm{L}, \mathrm{n}=9$ ) of the drug within $30 \mathrm{sec}$ from the end of the first trial (postacquisition treatment) improves memory. A higher dose $(500 \mathrm{ng} / 0.5 \mu \mathrm{L}$, $n=12$ ) has no effect. The points indicate the number of visits for each arm (mean \pm s.e.m.). Intertrial interval, 180 min. ${ }^{*} P<0.05$ compared with the other two arms (Scheffè post hoc test). rather than to the blockade of the effects of the full agonist 5-HT.

Gasbarri et al. (1999) revealed that serotonergic terminals, deriving primarily from the $\mathrm{B} 7$ cell group of the dorsal raphe nucleus, make putative synaptic contacts with cholinergic neurons of the NBM. Those authors thus provided neuroanatomical evidence of a direct functional interaction between the two neurotransmitter systems in the basal forebrain. Our results support these findings, indicating the presence and the prominent role of the 5-HT4 receptors within this brain area.

On the basis of the data reported here, it may be hypothesized that the ameliorative effect of RS67333 on place recognition memory, caused by 5 -HT4 activation, results from the potentiation of the cholinergic NBM-cortical pathway. Other mixed 5-HT3 antagonists/5HT4 agonists, the benzimidazolones BIMU-1 and BIMU-8, in fact, increased extracellular levels of acetylcholine (ACh) in rat microdialysis studies (Consolo et al. 1994), and BIMU-8 enhanced

that in our experiments this compound reverses the memory improvement caused by RS67333 administration, a possible involvement of central $\sigma 1$ and $\sigma 2$ receptors in the observed behavioral effects of RS67333 may be rejected.

The present findings are supported by previous results of Fontana et al. (1997), who investigated the systemic action of RS67333 in a rat model of spatial memory, the Morris water maze. They observed a procognitive effect of the drug, attributable to central 5-HT4 activation, as it was abolished by pretreatment with RS67532, a selective receptor antagonist.

More recent studies add further evidence to the memory-enhancing properties of RS67333. Lelong et al. (2001) reported that the drug improved the learning rate of animals subjected to various training regimens in the Morris water maze. Interestingly, Lamirault and Simon (2001), using the same paradigm employed in our experiments, demonstrated that the systemic administration of RS67333 before the acquisition phase enhances place recognition memory in young-adult and old rats.

In the present study the preacquisition, postacquisition, and preretrieval administration of $300 \mathrm{ng}$ of the 5-HT4 antagonist RS39604 into the NBM did not affect memory by itself, being able to reverse the procognitive effect of RS67333. This finding indicates that, in our experimental conditions, the behavioral performance is associated, at the level of the NBM, with a low release of endogenous 5-HT. Therefore the finding demonstrates that the effect of the partial agonist RS67333 is attributable to the activation of 5-HT4 receptors the ACh efflux in electrically stimulated slices of cerebral cortex, hippocampus, and NBM (Siniscalchi et al. 1999). In addition, the administration of RS67333 reverted the cognitive deficit induced by atropine, a nonselective muscarinic antagonist, in the Morris water maze (Fontana et al. 1997).

The cholinergic input to the neocortical mantle is believed to be of crucial importance in cortical functions. In addition, the degeneration of cholinergic neurons of the basal forebrain and the loss of presynaptic cortical cholinergic markers are asso-

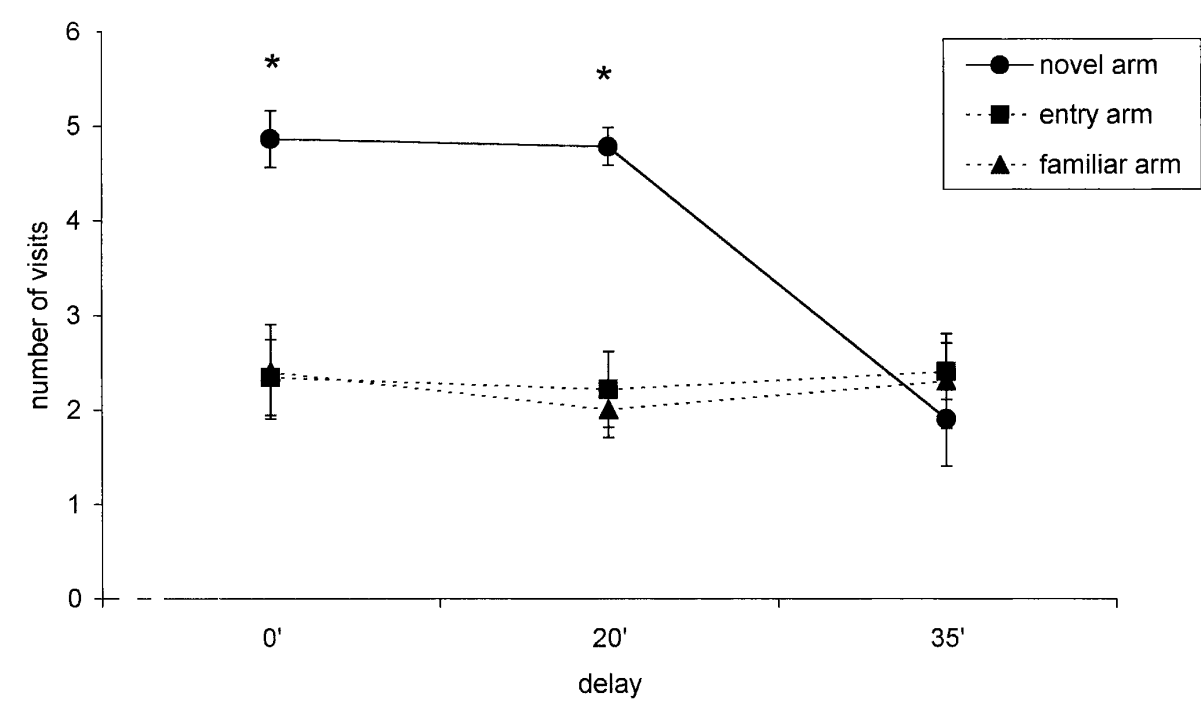

Figure 5 Time-dependency of the ameliorative effect of RS67333 $(n=27)$ on place recognition memory: The same dose $(200 \mathrm{ng} / 0.5 \mu \mathrm{L})$ of the drug was injected into the NBM $30 \mathrm{sec}(\mathrm{n}=9), 20 \mathrm{~min}$ $(n=8)$, or $35 \mathrm{~min}(n=10)$ after the end of the acquisition trial to three different groups of rats. The statistical analysis of data (see the text for details) indicates that the procognitive effect of RS67333 disappears when the drug is injected with a 35-min delay. The points indicate the number of visits for each arm (mean \pm s.e.m.). Intertrial interval, $180 \mathrm{~min}$. ${ }^{*} P<0.05$ compared with the other two arms (Scheffè post hoc test). 


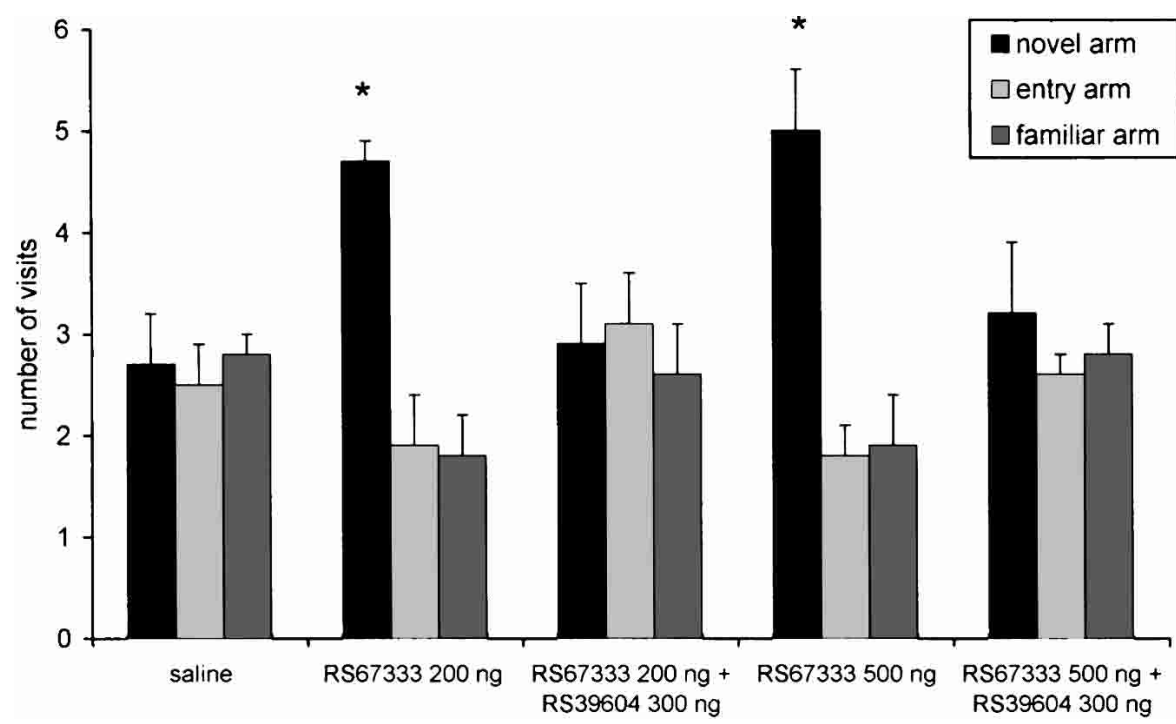

Figure 6 Place recognition memory: The procognitive effects of $200 \mathrm{ng}$ and $500 \mathrm{ng}$ of RS67333 infused preacquisition into the NBM area are abolished by prior treatment with $300 \mathrm{ng}$ of the selective 5HT4 antagonist RS39604. Intertrial interval, $180 \mathrm{~min} .{ }^{*} P<0.05$ compared with the other two arms (Scheffè post hoc test).

ciated with the cognitive decline in patients with Alzheimer's disease. In this respect, the potentiating action of 5-HT4selective agonists on cholinergic function and their memory-enhancing effects might have significant implications for the development of novel approaches to the treatment of cognitive disorders.

Our data also indicate that the procognitive effect of RS67333 appears when the drug is injected before and immediately after the first trial of the place recognition task. Thus, the activation of 5-HT4 receptors facilitates the acquisition and the consolidation of spatial information. In contrast, the memory recall is not affected by the 5-HT4 agonist.

Interestingly, the postacquisition effect of RS67333 on place recognition was time-dependent, because the promnestic action of RS67333 disappeared when the intra-NBM infusion of the drug was made $35 \mathrm{~min}$ after the end of the first trial. These results indicate that, in the NBM, the biochemical events triggered by 5 -HT4 receptors activation could play a role in the early period of memory consolidation. In this respect, the observation that the immediate postacquisition phase $(<30 \mathrm{~min}$ after training) is also subjected to the modulatory effects of central muscarinic and nicotinic synapses (Izquierdo and Medina 1997) is in line with the hypothesis of cholinergic-mediated effects of 5-HT4 receptor agonists on memory.

Although the present findings support and extend those reported by other workers, they are in contrast to the results of Meneses and Hong (1997). Those authors reported that the pretraining activation of 5-HT4 receptors enhanced the acquisition, whereas the posttraining activation of 5-HT4 receptors impaired the consolidation, of an appeti(Scheffè post hoc test). tive lever-press response in rats treated with BIMU 1 and BIMU 8.

The apparent discrepancy between the data of Meneses and Hong and the present results can be easily explained by taking into account differences in behavioral task (operant task vs. spatial, short-term memory task) and experimental protocol employed (repeated training vs. single training trial, 24 -h retention interval vs. 180-min retention interval, intra-NBM drug infusion vs. systemic administration). Moreover, our postacquisition data are in agreement with those reported by Galeotti et al. (1998), who observed, in a mouse passive avoidance test, a facilitation of memory after posttraining administration of BIMU 1 and BIMU 8, two mixed 5-HT3 antagonists/5-HT4 agonists.

In conclusion, the experiments reported here demonstrate that: (1) The activation of 5-HT4 receptors enhances the acquisition and the consolidation but not the recall of spatial memory; (2) 5-HT4 receptors are located within the NBM and may play a role in learning and memory; and (3) the procognitive effect of RS67333 is likely due, at least in part, to the potentiation of the activity of cholinergic NBM-cortical pathways.

Taken together, these findings seem to indicate that the administration of selective 5-HT4 receptor agonists in conjunction with acetylcholinesterase inhibitors may provide a more effective treatment strategy for age-related cognitive impairments compared to therapies designed to potentiate selectively the cholinergic synaptic transmission. Moreover, a recent study by Lamirault et al. (2003) regarding the effects on place and object recognition memory of a combined treatment with RS67333 and galanthaminium bromide, a new cholinesterase inhibitor, strongly supports this hypothesis.

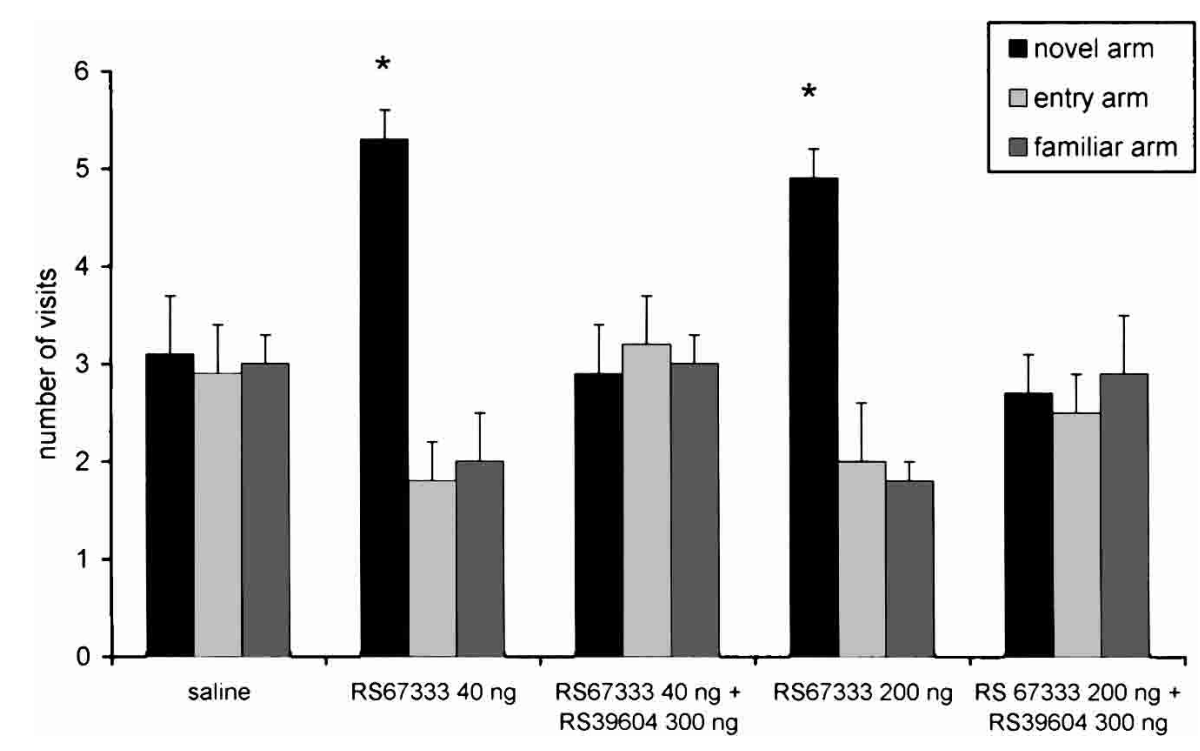

Figure 7 Place recognition memory: The procognitive effects of $40 \mathrm{ng}$ and $200 \mathrm{ng}$ of RS67333 infused postacquisition into the NBM area are abolished by prior treatment with $300 \mathrm{ng}$ of the selective 5HT4 antagonist RS39604. Intertrial interval, $180 \mathrm{~min} .{ }^{*} P<0.05$ compared with the other two arms 


\section{MATERIALS AND METHODS}

\section{Rats}

Male Wistar rats (Charles River) weighing 180-200 g were used as subjects. They were housed in a temperature-controlled colony room $\left(21^{\circ} \pm 1^{\circ} \mathrm{C}\right)$ with free access to food and water and were maintained four per cage under standard laboratory conditions. Before surgery, each rat was submitted to daily handling for at least $1 \mathrm{wk}$. All experiments were carried out in accordance with the European Communities Council Directive of 24 November 1986 (86/609/EEC). All efforts were made to minimize animal suffering and to reduce the number of animals used.

\section{Surgery}

The rats were anesthetized with Domitor $(0.5 \mathrm{mg} / \mathrm{kg})$ plus ketamine $(75 \mathrm{mg} / \mathrm{kg})$ i.p., placed in a stereotaxic apparatus (Stoelting Stellar), and implanted bilaterally with chronic indwelling guide cannulae (23-gauge) positioned $1 \mathrm{~mm}$ above the final injection sites. The coordinates were $\mathrm{AP}=-1.3, \mathrm{~L}= \pm 2.8$, and $\mathrm{V}=-6.3$ relative to bregma (Paxinos and Watson 1998). The guide cannulae were held in place with stainless steel screws and dental acrylic cement and were occluded with removable stainless steel wire pins. Postoperatively, the animals were given free access to food and water and were allowed to recover for $1 \mathrm{wk}$ before behavioral testing.

\section{Apparatus and Behavioral Task}

The apparatus used was a Y-maze made of opaque Plexiglas. The maze was placed in a sound-isolated room equipped with constant illumination (a $60-\mathrm{W}$ lamp located $150 \mathrm{~cm}$ above the center of the maze). Several visual cues were placed in the testing room near the maze and were kept constant during all the experiments. The test of place recognition (Dellu et al. 1992) consisted of two trials, separated by different retention intervals (in saline experiments) or by a fixed retention interval (in drug experiments). Each rat was subjected to this behavioral paradigm only once. In the first trial (acquisition trial), one arm of the maze was closed with a guillotine door, and the rat was allowed to visit the other two open arms for $10 \mathrm{~min}$. During the second trial (testing trial), the rat had free access to the three arms and was allowed to explore the maze for $5 \mathrm{~min}$. At the beginning of both trials, each rat was placed in the same arm (the entry arm) and was oriented in the direction opposite of the center of the maze. In our experiments, the entry arm was changed randomly to reduce the influence of individual external cues on animal performance. Similarly, the position of the novel arm (the arm closed by the guillotine door in the acquisition trial) was kept in a random order at the left for half the rats and at the right of the entry arm for the other half. During the testing trial, the numbers of visits of the novel, familiar, and entry arms were recorded separately, and the values so obtained are expressed as means \pm SEM. Recognition was assumed to have occurred when the rat made more visits to the novel arm than the other two familiar arms. After each trial, the maze was carefully cleaned to eliminate olfactory stimuli.

\section{Drugs and Injection Procedure}

RS67333 hydrochloride and RS39604 hydrochloride (Tocris Cookson) were dissolved in saline ( $\mathrm{NaCl} 0.9 \%$ solution) and prepared immediately prior to use. The control group rats received only the saline. Intracranial administration was made by two infusion pumps (CMA model 102) connected to 28-gauge injection cannulae with polyethylene tubing. The injection cannulae were inserted to a depth of $1 \mathrm{~mm}$ below the tips of the guide cannulae, and the solutions were infused at a rate of $2 \mu \mathrm{L} / \mathrm{min}$ for $15 \mathrm{sec}$. The injection cannulae were left in place for an additional 30 -sec period to promote diffusion.

In control experiments, three groups of saline-treated rats were tested at increasing time intervals $(60,120$, and $180 \mathrm{~min})$ from the acquisition trial. Within each group, the saline was administered randomly preacquisition, postacquisition, or pre- retrieval, because preliminary experiments indicated no differences among these treatments. The drugs were administered 2 min prior to the beginning of the first trial (preacquisition treatment) or the second trial (preretrieval treatment) or within $30 \mathrm{sec}$ from the end of the first trial (postacquisition treatment).

To estimate the range of drug diffusion following local infusion, blue dye (Fast Blue, Dupont) was dissolved in $0.9 \%$ saline at a concentration of $25 \mu \mathrm{g} / 0.25 \mu \mathrm{L}$ and infused at the same rate as RS67333 and RS39604 (Fig. 1).

\section{Histology}

At the conclusion of testing, all operated animals were anesthetized and the brains were perfused with $10 \%$ formalin-saline solution. The brains were removed, postfixed in 30\% formalin for $48 \mathrm{~h}$, and sectioned into $80-\mu \mathrm{m}$ sections. Finally the sections were stained with cresyl-violet for histological verification of the injection sites (Fig. 1).

\section{Data Analysis}

The global analysis of experimental data was performed by a mixed design between-within ANOVA. Within each group, the presence of a significant arm effect, that is, the rats' for a particular arm, was evaluated by one-way ANOVA with repeated measures followed, when appropriate, by post hoc two-by-two comparisons (Scheffè test). The significance threshold was $P=0.05$.

\section{ACKNOWLEDGMENTS}

The publication costs of this article were defrayed in part by payment of page charges. This article must therefore be hereby marked "advertisement" in accordance with 18 USC section 1734 solely to indicate this fact.

\section{REFERENCES}

Baxter, M.G., Bucci, D.J., Gorman, L.K., Wiley, R.G., and Gallagher, M. 1995. Selective immunotoxic lesions of the basal forebrain cholinergic cells: Effects on learning and memory in rats. Behav. Neurosci. 109: 714-722.

Cassel, J.C. and Jeltsch, H. 1995. Serotoninergic modulation of cholinergic function in the central nervous system: Cognitive implications. Neuroscience 69: 1-41.

Consolo, S., Arnaboldi, S., Giorgi, S., Russi, G., and Ladinsky H. 1994. 5 -HT4 receptor stimulation facilitates acetylcholine release in rat frontal cortex. Neuroreport 5: 1230-1232.

Dekker, A.J., Connor, D.J., and Thal, L.J. 1991. The role of cholinergic projections from the nucleus basalis in memory. Neurosci. Biobehav. Rev. 15: 299-317.

Dellu, F., Mayo, W., Cherkaoui, J., Le Moal, M., and Simon, H. 1992. A two-trial memory task with automated recording: Study in young and aged rats. Brain Res. 588: 132-139.

Eglen, R.M., Bonhaus, D.W., Johnson, L.G., Leung, E., and Clark, R.D. 1995a. Pharmacological characterization of two novel and potent 5-HT4 receptor agonists, RS67333 and RS67506, in vitro and in vivo. Br. J. Pharmacol. 115: 1387-1392.

Eglen, R.M., Wong, E.H.F., Dumuis, A., and Bockaert, J. 1995b. Centra 5-HT4 receptors. Trends Pharm. Sci. 16: 391-398.

Fontana, D.J., Daniels, S.E., Wong, E.H.F., Clark, R.D., and Eglen, R.M. 1997. The effects of novel, selective 5-hydroxytryptamine $(5-\mathrm{HT})_{4}$ receptor ligands in rat spatial navigation. Neuropharmacology 36: 689-696.

Galeotti, N., Ghelardini, C., and Bartolini, A. 1998. Role of 5-HT4 receptors in the mouse passive avoidance test. J. Pharmacol. Exp. Ther. 286: 1115-1121.

Gasbarri, A., Sulli, A., Pacitti, C., and McGaugh, J.L. 1999. Serotoninergic input to cholinergic neurons in the substantia innominata and nucleus basalis magnocellularis in the rat. Neuroscience 91: 1129-1142.

Hedge, S.S., Bonhaus, D.W., Johnson, L.G., Leung, E., Clark, R.D., and Eglen, R.M. 1995. RS39604: A potent, selective and orally active 5-HT4 receptor antagonist. Br. J. Pharmacol. 115: 1087-1095.

Izquierdo, I. and Medina, J. 1997. Memory formation: The sequence of biochemical events in the hippocampus and its connection to activity in other brain structures. Neurobiol. Learn. Mem. 68: $285-316$.

Lamirault, L. and Simon, H. 2001. Enhancement of place and object recognition memory in young adult and old rats by RS67333, a partial agonist of 5-HT4 receptors. Neuropharmacology 41: 844-853. 
Lamirault, L., Guillou, C., Thal, C., and Simon, H. 2003. Combined treatment with galanthaminium bromide, a new cholinesterase inhibitor, and RS 67333, a partial agonist of 5-HT4 receptors, enhances place and object recognition in young adult and old rats. Prog. Neuro-Psychopharmacol. Biol. Psych. 27: 185-195.

Leanza, G., Muir, J., Nilsson, O.G., Wiley, R.G., Dunnett, S.B., and Bjorklund, A. 1996. Selective immunolesioning of the basal forebrain cholinergic system disrupts short term memory in rats. Eur. J. Neurosci. 8: 1535-1544.

Lelong, V., Dauphin, F., and Boulouard, M. 2001. RS 67333 and D-cycloserine accelerate learning acquisition in the rat. Neuropharmacolog. 41: 517-522.

Letty, S., Child, R., Dumuis, A., Pantaloni, A., Bockaert, J., and Rondouin, G. 1997. 5-HT4 receptors improve social olfactory memory in the rat. Neuropharmacology 36: 681-687.

Marchetti, E., Dumuis, A., Bockaert, J., Soumireu-Mourat, B., and Roman, F.S. 2000. Differential modulation of 5-HT4 receptor agonists and antagonist on rat learning and memory. Neuropharmacology 39: 2017-2027.

Marchetti-Gauthier, E., Roman, F.S., Dumuis, A., Bockaert, J., and Soumireu-Mourat, B. 1997. BIMU1 increases associative memory in rats by activating 5-HT4 receptors. Neuropharmacology 36: 697-706.

Meneses, A. and Hong, E. 1997. Effects of 5-HT4 receptor agonists and antagonists in learning. Pharmacol. Biochem. Behav. 56: 347-351.
Paxinos, G. and Watson, C. 1998. The rat brain in stereotaxic coordinates, 4th edition, Academic Press, New York.

Reynolds, G.P., Mason, S.L., Meldrum, A., De Keczer, S., Parnes, H., Eglen, R.M., and Wong, E.H.F. 1995. 5-Hydroxytryptamine (5-HT) receptors in post mortem human brain tissue: Distribution, pharmacology and effects of neurodegenerative diseases. $\mathrm{Br} . J$. Pharmacol. 114: 993-998.

Siniscalchi, A., Badini, I., Beani, L., and Bianchi, C. 1999. 5-HT4 receptor modulation of acetylcholine outflow in guinea pig brain slices. Neuroreport. 10: 547-551.

Sirvio, J., Riekkinen, P., Jakala, P., and Riekkinen, P.J. 1994. Experimental studies on the role of serotonin in cognition. Prog. Neurobiol. 43: 363-379.

Steckler, T. and Sahgal, A. 1995. The role of serotoninergic-cholinergic interactions in the mediation of cognitive behaviour. Behav. Brain Res. 67: 165-199.

Waeber, C., Sebben, M., Bockaert, J., and Dumuis, A. 1996. Regional distribution and ontogeny of 5-HT4 binding sites in rat brain. Behav. Brain Res. 73: 259-262.

Received July 24, 2003; accepted in revised form August 13, 2003.

\section{Learning \& Memory}




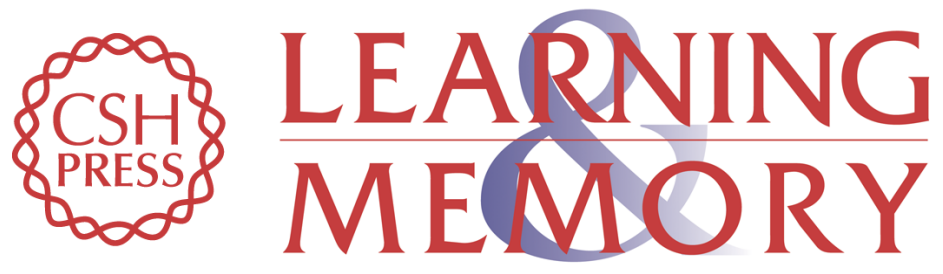

\section{Acquisition, Retention, and Recall of Memory After Injection of RS67333, a 5-HT4 Receptor Agonist, Into the Nucleus Basalis Magnocellularis of the Rat}

Marco Orsetti, Anna Dellarole, Simona Ferri, et al.

Learn. Mem. 2003, 10:

Access the most recent version at doi:10.1101/lm.67303

References This article cites 25 articles, 1 of which can be accessed free at: http://learnmem.cshlp.org/content/10/5/420.full.html\#ref-list-1

License

Email Alerting

Receive free email alerts when new articles cite this article - sign up in the box at the Service top right corner of the article or click here. 